“ (C) 2016 IEEE. Personal use of this material is permitted. Permission from IEEE must be obtained for all other uses, in any current or future media, including

reprinting/republishing this material for advertising or promotional purposes, creating new collective works, for resale or redistribution to servers or lists, or reuse of any copyrighted component of this work in other works." 


\title{
Singly-fed Shaped Planar Inverted-F Antenna for Circular Polarization
}

\author{
Farhad Gozasht, Anantasri Boddupalli, Steve S. H. Ling, Ananda S. Mohan \\ Center for Health Technologies (CHT), Faculty of Engineering and Information Technology (FEIT) \\ University of Technology Sydney (UTS), NSW, Australia. \\ Ananda.Sanagavarapu@uts.edu.au
}

\begin{abstract}
We propose a singly-fed planar inverted-F antenna (PIFA), with double-shorting planes and a tapered patch for radiating circular polarization. FEKO $^{\circledR}$ simulations are employed to optimize the geometry of the antenna. The antenna prototype resonates at $2.52 \mathrm{GHz}$ and has a measured impedance bandwidth of around $240 \mathrm{MHz}$. The calculated $3 \mathrm{~dB}$ axial ratio bandwidth falls within the impedance bandwidth, demonstrating satisfactory circular polarization characteristics.
\end{abstract}

Keywords-PIFA, circular polarization, axial ratio.

\section{INTRODUCTION}

The planar inverted-F antenna (PIFA) has many advantages such as easy fabrication, low manufacturing cost and simple structure. The PIFAs were initially designed extensively for use in mobile phones [1]. This was mainly due to their ability to resonate at quarter-wavelength, thus reducing the space required and also, their omnidirectional radiation. In recent years, the PIFAs have also been proposed for other applications, ranging from radio frequency identification (RFID) systems to implantable communications [2]. But the conventional PIFA has a narrow bandwidth and is typically designed for linear polarization. In many wireless applications, it is preferred to have PIFAs with wider bandwidths. Also, for some applications such as RFID, global positioning systems (GPS), etc., PIFA with circular polarization (CP) radiation is preferred [3]. Even for wireless communications, circularly polarized PIFA can help to mitigate the losses caused by multipath effects. However, the design of PIFA with CP has not been adequately explored.

The basic PIFA consists of a ground plane, a top plate element or radiation patch, a feed wire attached form the ground plane to the top plate and a shorting plane connected between the ground and top plate. In general, the most frequently engaged method to broaden the bandwidth is to raise the height of the shorting plane, which is equivalent to increasing the volume. Another PIFA with compact size and low SAR was proposed in [4], albeit only for linear polarization.

In this paper, we offer a compact and singly-fed PIFA with tapered patch having a wide bandwidth in the $2.45 \mathrm{GHz}$ ISM band. A novel dual-shorting technique is employed to radiate $\mathrm{CP}$, which also provides structural support for the radiating element. We have designed and fabricated the PIFA prototype to investigate impedance bandwidth, axial ratio (AR) and radiation performance of the proposed antenna

\section{DESIGN PROCEDURE}

The resonant frequency can be estimated by using (1) when designed on air substrate $(\varepsilon r=1)$ given by

$$
f_{0}=\frac{c_{0}}{4\left(L_{1}+L_{2}+H-W\right)}
$$

where, $\mathrm{c} 0$ is the velocity of light, L1 and L2 are the length and width, respectively, of the radiating element and $\mathrm{H}$ and $\mathrm{W}$ are the height and width, respectively, of the shorting plane.

Fig. 1 illustrates the configuration of the proposed PIFA. The antenna dimensions are $70 \times 30 \times 6 \mathrm{~mm}^{3}$ and is excited near the shorting plane at the back. The patch is partially tapered on one side and is connected to the ground with the help of two shorting planes. The shorting planes are placed away from each other and at opposite ends of the patch. We used the $\mathrm{FEKO}^{\circledR}[5]$ simulations to empirically optimize the antenna geometry to resonate around $2.45 \mathrm{GHz}$ with a minimum band width of 100Mhz.

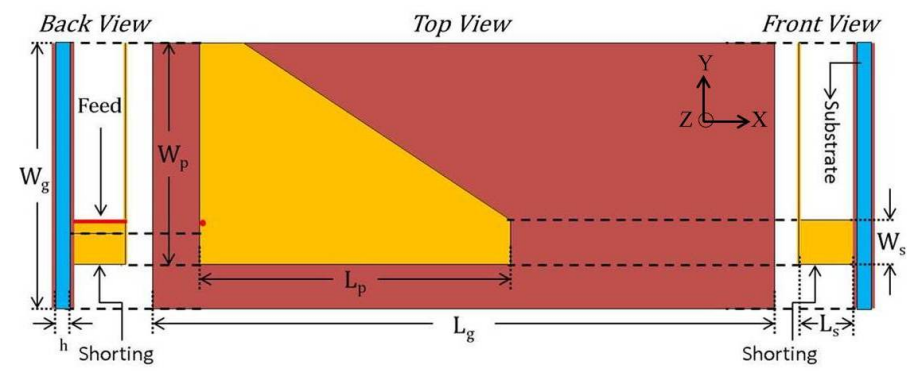

Fig. 1. Schematic of the proposed antenna.

\section{RESULTS AND DISCUSSION}

The antenna was fabricated with the air substrate and found to resonate at $2.52 \mathrm{GHz}$. While the calculated $-10 \mathrm{~dB}$ impedance bandwidth was $100 \mathrm{MHz}$, the measured bandwidth was around $240 \mathrm{MHz}$, as shown in figs. 2 and 3 . The calculated $3 \mathrm{~dB}$ AR bandwidth also falls within the impedance bandwidth thereby demonstrating good $\mathrm{CP}$ performance, as shown in fig. 4. The antenna has a simple coaxial feeding structure feeding the upper patch through the inner conductor. 


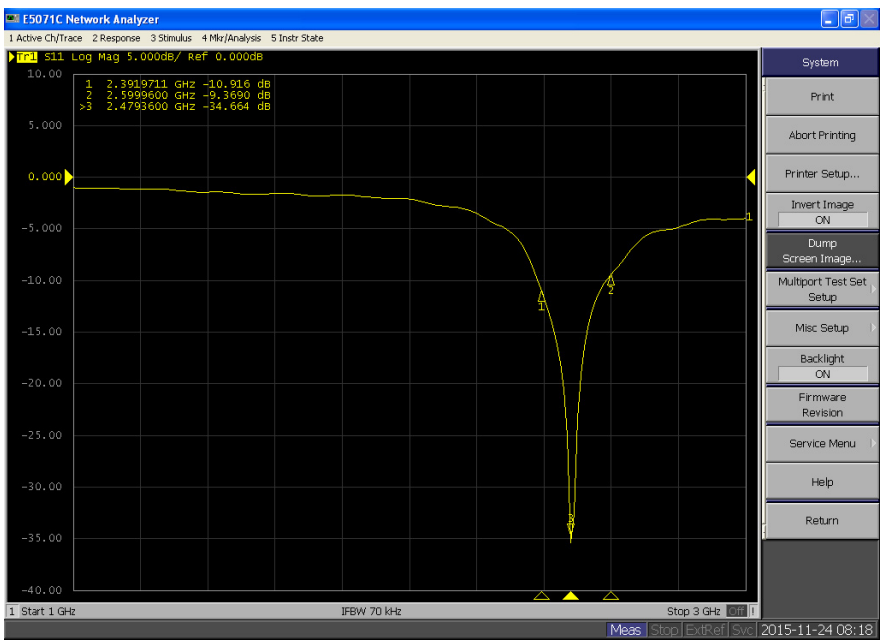

Fig. 2. Return loss measurement of the antenna model.

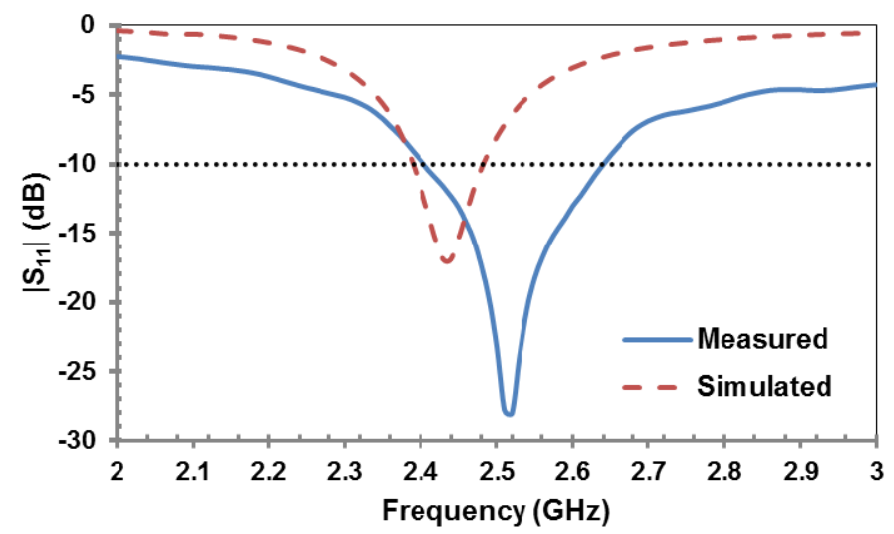

Fig. 3. Simulated and measured $\left|\mathrm{S}_{11}\right|$ characteristics.

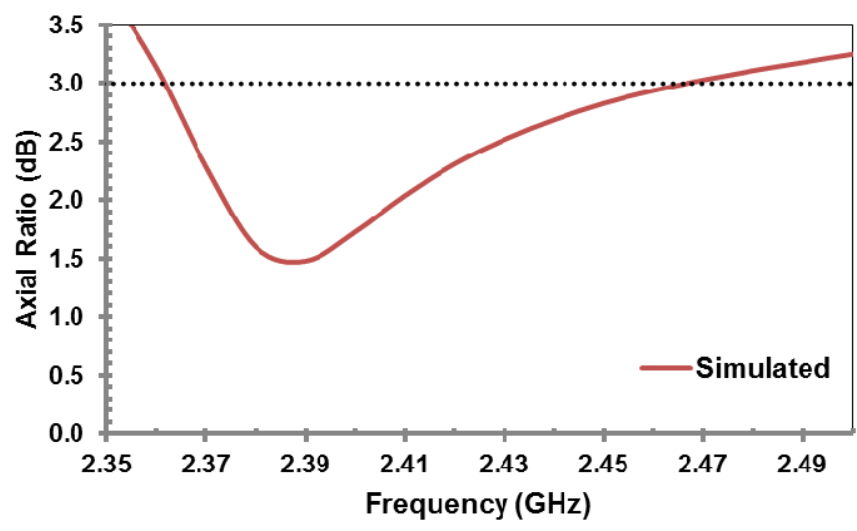

Fig. 4. Simulated axial ratio.

The 3-D AR is shown in fig. 5 which reveals that the CP exhibited by the antenna is omnidirectional. This is very advantageous for the wireless applications. The peak antenna gain obtained from $\mathrm{FEKO}^{\circledR}$, is shown in fig. 6. All these indicate superior performance of the proposed circularly polarized PIFA.

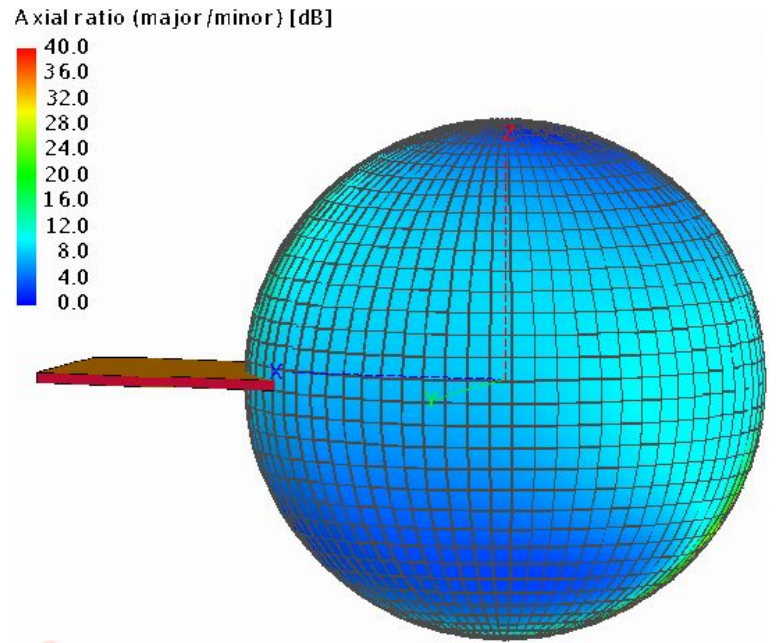

Fig. 5. 3-D axial ratio.

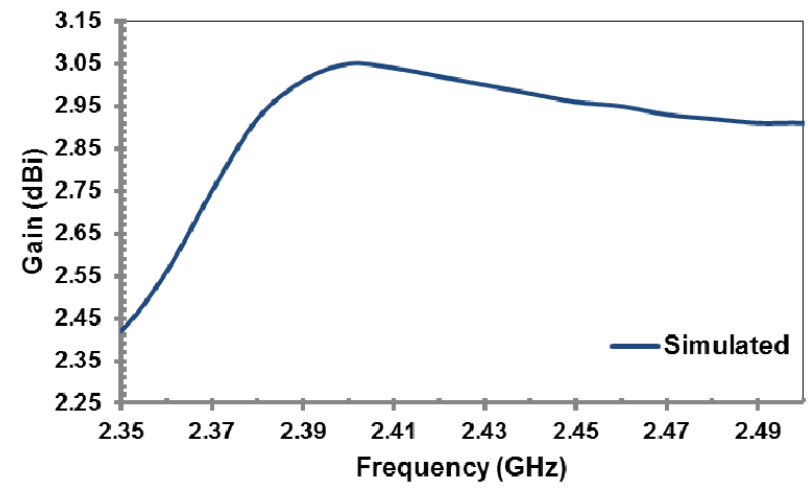

Fig. 6. Calculated peak antenna gain.

\section{CONCLUSION}

A singly-fed, compact PIFA with a tapered patch and dual shorting planes is proposed for circularly polarized radiation. The fabricated prototype resonates at $2.52 \mathrm{GHz}$ with a wide impedance bandwidth of $240 \mathrm{MHz}$. The calculated axial ratio and gain are presented. These render the antenna to be a suitable candidate for use in current and future wireless applications.

\section{REFERENCES}

[1] C.R. Rowell and R.D. Murch, "A capacitively loaded PIFA for compact mobile telephone handsets," IEEE Trans. Antennas Propagat., vol. 45, pp. 837-842, May 1997.

[2] C-H. Lin, K. Saito, M. Takahashi, and K. Ito, "A compact planar inverted-F antenna for $2.45 \mathrm{GHz}$ on-body communications," IEEE Trans. Antennas Propagat., vol. 60, no. 9, pp. 4422-4426, July 2012.

[3] Y. Yao, X. Wang, X. Chen, J. Yu, and S. Liu, "Novel diversity/MIMO PIFA antenna with broadband circular polarization for multimode satellite navigation," IEEE Antennas and Wireless Propagation Letters, vol. 11, pp. 65-68, Jan 2012.

[4] J.D. Park, H.D. Kim, and H.D. Choi, "A low SAR design of folder type handset with dual antennas," IEEE APS International Symposium, vol. 2, pp. 1005-1008, 2003.

[5] FEKO $^{\circledR}$ - EM Simulation Software (v7.1), Altair Engineering (https://www.feko.info) 